\title{
Let's Talk About Reflection at Work
}

Viktoria Pammer

Know-Center GmbH and Graz University of Technology, Knowledge

Technologies Institute

Inffeldgasse 13/VI

Austria - $8010 \mathrm{Graz}$

Vpammer@know-center.at

Birgit Krogstie

Department of Informatics and e-learning, Norwegian University of

Science and Technology

Norway - 7491 Trondheim

birgit.r.krogstie@hist.no

Michael Prilla

Human Centered Information Systems, Department of Informatics, Technical University of Clausthal

Julius-Albert-Str. 4

Germany - 38678 Clausthal

michael.prilla@tu-clausthal.de

Viktoria Pammer is assistant professor at the Knowledge Technologies Institute, Graz University of Technology and area manager at the KnowCenter. She is responsible for teaching, research and innovation in the field of computer-supported working, learning and creativity, with an emphasis on knowledge work settings. Viktoria holds a $\mathrm{PhD}$ and an MSc (both with distinction) from the Graz University of technology. She has published around 60 scientific papers in international journals, conferences and workshops, and regularly serves as PC member in international conferences such as the ECTEL.

Birgit R. Krogstie is Associate Professor at the Norwegian University of Science and Technology in Trondheim. She is teaching and supervising in the areas of Computer Supported Cooperative Work and e-learning and is particularly interested in reflection at work and in higher education, peer assessment in higher education, and project based learning. She has published in conferences like ECSCW, EC-TEL and ICSE and chairs the program committee for the Norwegian Conference on Education and Didactics in IT. 
Author

Michael Prilla is Professor of Human Centered Information Systems at the Technical University of Clausthal, Germany. He has published more than 90 research papers, articles and book chapters. His research interests are socio-technical systems design, human computer interaction, cooperation support, learning and reflection at work, ubiquitous computing and the convergence of digital and physical interaction. He has published in CACM and in conferences like ACM Group, ECIS and ECSCW. He is deputy chair of the German special interest group on CSCW and serves on committees for conferences like ACM Group, CSCW, ECSCW and CHI. 


\begin{abstract}
Reflective learning is a mechanism to turn experience into learning. As a mechanism for self-directed learning, it has been found to be critical for success at work. In the workplace, reflective learning is relevant to everyone - the knowledge workers, teams, and the organisation as a whole. In this paper, we lay out the terminology and a process model of (computer-supported) reflective learning at work that we have developed in parallel to observing reflection in practice, designing information and communication technology for reflective learning at work, and trialling developed technology in multiple field trials. The model emphasises aspects that are in particular relevant in the workplace: In the terminology this is visible by clarification of reflection scopes (who should learn? An individual, a group, or the organisation), learning processes (individual vs. collaborative), and learning by different social entities (an individual, a group or an organisation). In the process representation this is visible by the emphasis on information that is handed over between stages, and the explicitly modelling of triggers for follow-up reflection cycles. This paper also discusses the subtleties of differentiating between reflection participants, reflection scope, and who actually learns; the specificity of our research for workplace learning, the relevance of these theoretical considerations for designing information and communication technology, and the role of data and materials in the reflection process.
\end{abstract}

\title{
Introduction
}

Reflective learning is a mechanism to turn experience into learning. Boud et al. (1985) phrase this as "those intellectual and affective activities in which individuals [...] explore their experiences in order to lead to new understandings and appreciations". Similarly, Daudelin (1996) describes reflection as "the process of stepping back from an experience to ponder, carefully and persistently, its meaning to the self through the development of inferences; learning is the creation of meaning from past or current events that serves as a guide for future behavior".

As a mechanism that is suitable for self-directed learning, reflective learning has been found to be critical for success at work (Eraut, 2004; Knipfer et al, 2012). In many cases, work-relevant knowledge is neither available explicitly nor curated as learning material. Reflection on the other hand builds upon experience which may or may not already be "post-processed" in the sense of being analysed, given meaning to, and distilled into best practice or similar forms of more easily transferrable knowledge. In this manner, reflection helps organisations handle competition and changing external factors (Cressey, 2006) by enabling 
adaptation and fuelling innovation (Høyrup, 2010).

The authors of this paper have worked extensively over the last few years on the topic of computer-supported reflective learning at work, and base this paper on several previously published research articles, most notably the following, in chronological order: Pammer et al., 2011; Krogstie et al., 2012; Prilla et al., 2012; Krogstie et al., 2013, Prilla et al., 2013b. With this paper we synthesize our previous contributions, thus providing a coherent theory of reflective learning at work, which is based on empirical work, participatory technology design work, and field trials of developed technology. The present paper describes as our core theory of reflective learning at work an expanded and synthesized terminology and a rephrased succinct description of reflective learning in relation to working as a repeated cyclic connection (the CSRL model - originally described in Krogstie et al., 2013). In addition, this paper sums up avenues of research that spread out from this core theory; and discusses overarching issues that have not been discussed in this breadth in earlier publications. The paper concludes by putting our theory into the context of related work.

\section{Terminology}

Interdisciplinary discussions in the course of our work made apparent that different communities and different publications mean different things when referring to 'reflective learning'. Reflective learning might denote the actual cognitive process, as visible in Boud et al.'s definition of reflective learning "as those intellectual and affective activities in which individuals [...] explore their experiences in order to lead to new understandings and appreciations" (Boud et al., 1985). The cognitive process of reflective learning can be facilitated, encouraged guided etc. but cannot be triggered in a deterministic manner. Reflective learning might also denote an observable activity; which could be an individual process (such as writing a reflective diary, e.g., in Thorpe, 2004) or a social process (such as carrying out a project review, e.g., in Dingsøyr, 2005). Furthermore, 'reflection process' might denote a process that is spread over time, with multiple "reflections" on the same or a similar subject, or it might denote a single, compact "time slice" in which people reflected. Such discussions, and continued empirical and IT design work on the topic of reflective learning at work, led us to develop and use the following terminology, which we have found to be useful in order to discuss reflective learning: 


\section{Reflection Session}

A reflection session is defined by a time and a place; it is time-limited. In this time and place, one or more participants are present. Reflection sessions can be separate from or intertwined with work processes (cp. Schön, 1983; and his discussion of "reflection-in-action" and "reflectionon-action"). Reflection sessions can be prescheduled, or be initiated spontaneously at need (e.g., something critical happened) or convenience (e.g., on business travel).

A reflection session is defined through its participants, the sequence of methods applied; its trigger, content and outcome. All these elements are discussed below.

\section{Who reflects: Reflection Participants}

One or more people may participate in a reflection session. The term "participation" refers to active participation in the sense of actively thinking about the experience(s) reflected upon and seeking a solution. Such participation in the reflection of others is only possible if the participant shares some context with the other participants, that is, if the participant can reflect about experiences shared with him or her, as it concerns his or her own context. As opposed to that neutral people such as facilitators are not participants of such reflection but may be called "reflection helpers" (Prilla et al. 2013a). The reflection process is called "individual reflection process" if a single participant is present and "collaborative reflection process" if multiple participants are present.

\section{Reflection Method}

A reflection method is the procedure used to facilitate, encourage or guide reflection. Examples include re-constructing the timeline of events, asking (oneself, or a group) particular questions e.g. about what one would do differently the next time, and using a systematic approach to sharing and implementing insights in the future. It is not necessarily the case that the reflection method leads to the cognitive process of reflection in every participant in a reflection session; but the reflection method structures the observable activity of reflection.

\section{Reflection Trigger}

A reflection trigger starts the reflection process. A reflection trigger can be a state of dissonance, such as contradicting information, incongruent feelings, or interpersonal conflicts, leading to discomfort which in turn makes the individual or group reflect on the sources of the discomfort and possible solutions (cp Knipfer et al., 2012). A reflection trigger can also be 
more explicit, like a reminder or a request to reflect, for instance in the form of a specific question.

\section{Reflection Objective}

The reflection objective is often related to the dissonance that the reflection participants want to resolve, which can be a single experience in which something was unexpected, or a pattern of events over time which is somehow discomforting (e.g. the communication with a colleague or patient).

\section{Reflection Content}

The reflection content are all experiences and data relating to experiences relevant to the reflection object. In a collaborative reflection this means that for many reflection participants learning will come from vicarious (i.e. not one's own) experiences. Reflection content can be available in different forms: It can exist for instance as collected objective data about an experience (e.g., the temperature curve of a given day), as individual perceptions of an experience (perception of temperature, perception of qualities of relevant activities...), as artifacts resulting from the work process (e.g., software code, meeting reports).

\section{Who should learn - Reflection Scope}

One key characteristic of reflection is who should learn, i.e. in whose main responsibility the reflection object falls. We call this the reflection scope. The reflection scope often gives an indication who needs to participate in reflection and the set-up of single reflection sessions.

\section{Who learns: Individual, collaborative and organizational learning}

We understand learning very broadly as an intentional change in attitude, knowledge or behavior. These categories apply also to social entities like groups or organizations.

Following directly up on this understanding of what learning is, we understand individual learning to mean that an individual learns, collaborative learning to mean that a group learns, and organizational learning that an organization learns. By organizational learning we understand a change in the shared explicit knowledge within an organization and in the organization's work processes, be they formally or informally defined (in line with Kimmerle et al., 2010).

\section{Reflection Outcome}

The reflection outcome is the constructive result of a reflection process. It could be new knowledge, new perceptions, or new work processes. The 
reflection outcomes can either be made explicit, or not. If reflection outcomes are made explicit, they are often in the form of best practice or lesson learned documents; or annotations to previously existing documents.

\section{Describing Reflective Learning in Connection to (Work) Experience: The CSRL Model}

Descriptions of reflective learning activities in the workplace also require a model that describes the relationship between (work) experiences and reflective learning. Both the relation to past work experiences and to future work experiences are important; and the forward view is what distinguishes reflection from rumination.

Because this relationship both forward and backward, it seems natural to represent reflective learning as a cycle together with the experience(s) it refers to. The CSRL model at its core is therefore a simple cyclic model with stages strongly based on Boud et al., (1985); the CSRL model adds to this an emphasis on information that is handed over between stages, and rationales for initiating new cycles of reflection that we observed in practice.

The CSRL model as described below has been synthesized from literature but also significantly from own bottom-up theory building work that has led to the below CSRL model is (Krogstie, 2009; Krogstie et al., 2012a; Prilla et al., 2013b;). 


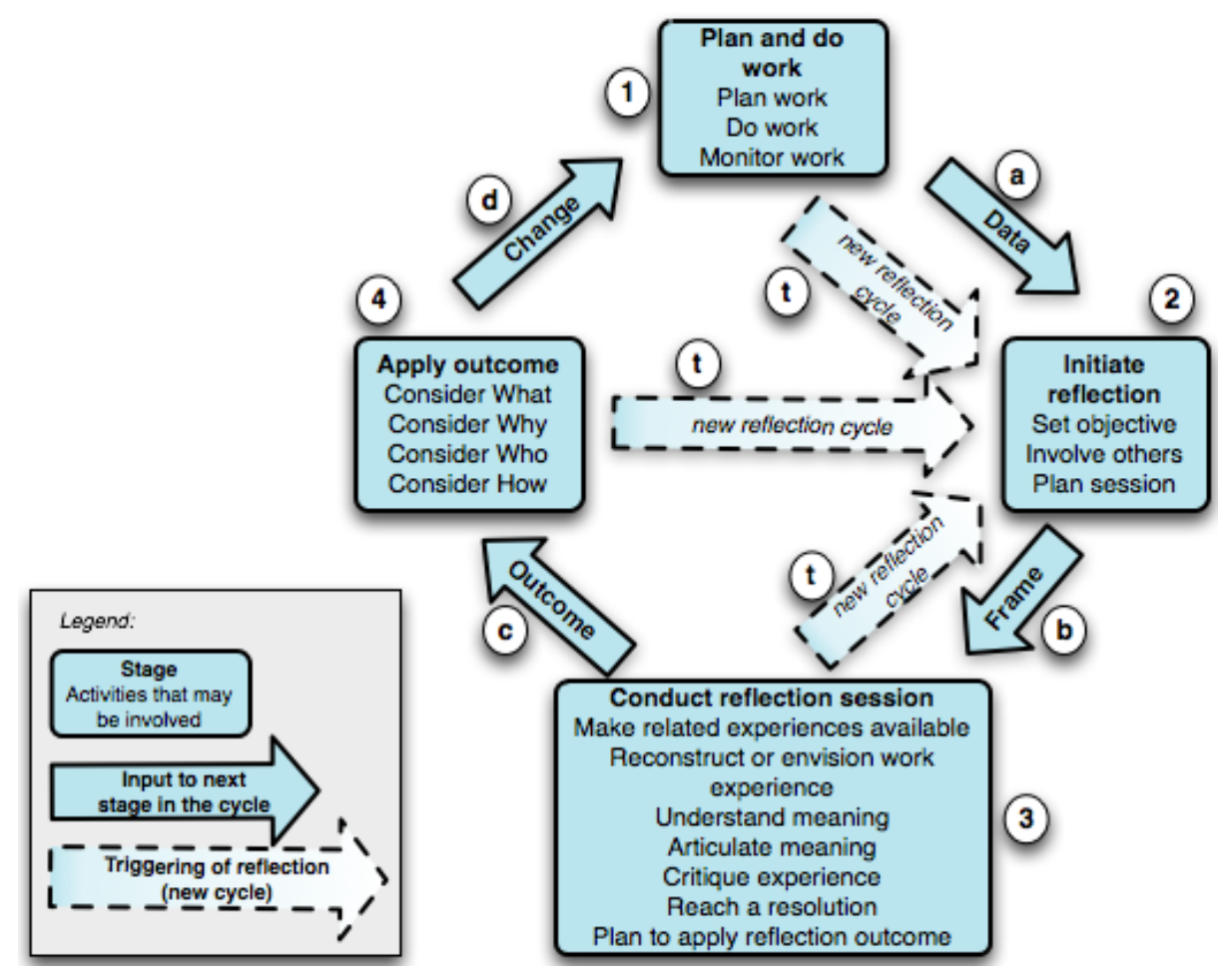

Figure 1. The CSRL model

\section{Stages in the CSRL Model}

The below description of stages has only been slightly re-phrased from Krogstie et al., 2013.

The plan and do work stage refers to conducting individual or group activity on the work arena, including everyday work, planning and monitoring. It also includes simulation of work in real or virtual environments. This stage explicitly refers not only to operative work activities but also to support activities like planning or monitoring work. The stage of initiating reflection consists of deciding to and setting up, however short, for reflection: This stage is sometimes brief, and not always conscious to the reflection participants. We have decided that this stage of setting the frame is relevant, for instance to differentiate between carefully planned reflection sessions, with an elaborate objective, vs. adhoc reflection sessions for instance. Most significantly, in this stage the reflection objective is set, the reflection participants are determined, and the reflection session is organised (additional work may be needed, such as organising a room for instance). 


\section{Let's Talk about Reflection at Work}

In the conduct reflection session stage reflection takes place based on the frame resulting from the reflection initiation. The session has an objective, a reflection topic, it may be facilitated and involves one or more participants. Most relevant activities in this stage are to make related experiences available to other reflection participants (in case of a collaborative reflection process); to reconstruct work experiences and envision them as they should ideally be in the future; to understand the experience in context; and articulate and critique this understanding. Finally, a resolution needs to be reached; which will be further concretised in the next stage. The reflection session results in an outcome.

In the apply outcome stage the reflection outcome is applied as changes on the work arena or is used as input to further reflection, or both. This may include involving others (e.g. the team or the manager), switching from collaborative to individual reflection (and vice versa) or applying reflection results to work.

\section{Information as Input/Output between stages}

The above simple cycle model describes different types of information that are passed between stages Figure 1 (a,b,c,d).

Data on work (a) is generated during work, and handed over to the initiate reflection stage: Data is needed to reconstruct and make sense of work experiences. It may be more or less contextualized, more or less filtered, and more or less abstracted. The data may result from user-initiated or automatic data gathering.

The frame for reflection (b) is created in the initiate reflection stage, and handed over to the conduct reflection session stage.

The reflection outcome (c) is generated in the conduct reflection session stage, and handed over to the apply outcome stage: The outcome may consist of several elements. It may be more or less explicit, and more or less clear with regard to implications for activity on the work arena. The change that is decided on in the apply outcome stage is handed over to the plan and do work stage (d): The change concretises the reflection outcome in terms of what activities (tasks, processes) and who (individuals, groups, roles, ...) are affected.

Triggers for New Reflection Cycles: Reflection in Practice as Multiple Iterations In empirical studies, we found multiple iterations of the single reflection cycle (e.g., Prilla et al., 2012; Krogstie et al., 2013a).

In the CSRL model this is represented by describing the possibility to start a new reflection cycle not only from within work, but also from within reflection, and from applying outcomes. This is very new in relation to literature, where mostly reflection is described only in terms of originating 
in work; in a wide sense, this may very often be true, but it fails to capture the fact that frequently relevant elements of the reflection process, such as participants, object, content, scope, etc. are changed so significantly during reflection, or when it comes to applying reflection outcomes, that it may be more useful to consider this as a new iteration of reflection. A new reflection cycle may involve different reflection participants (to bring in new expertise or executive power into the group); different reflection content (e.g., to bring new facts as basis for reflection into the discussion); or even a new object (e.g., if a significant clarification, or change in focus has been decided on).

In an earlier analysis of studies conducted in three different workplaces, we identified three categories of rationale for bringing new participants into a subsequent cycle of reflection that serve as triggers, namely (i) when reflection participants seek clarification or input from stakeholders not present in the current reflection session; (ii) when reflection participants seek support for implementing the reflection outcome, or (iii) when the goal of the reflection session was to create awareness of an issue by all reflection participants (Prilla et al., 2013b; see also Figure 2 below).

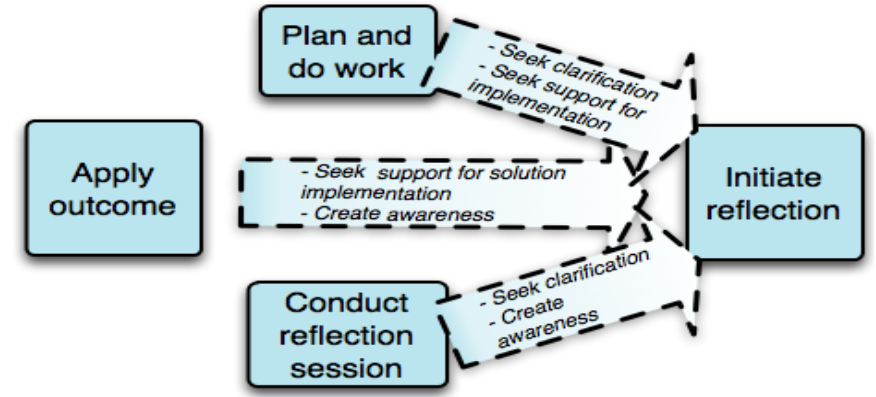

Figure 2. Rationale (triggers) for initiating a new reflection cycle.

\section{Spreading out from a Shared Understanding to Different Avenues of Interest}

Spreading out from the shared understanding of different elements of reflection and the core, single cycle process of reflection, we found different avenues of research to be highly interesting.

Push vs. Pull: Who is the Driver of a Reflection Process?

Following up on the observation that in complex work environments reflective learning often happens in multiple iterations, it is logical to ask about the driving force(s) for the reflection process.

We noticed two inherently different kinds of driving force/mechanism that drives reflection in our previous work, and described these as push and 
pull mechanisms in (Prilla et al., 2012): In the push mechanism, the reflection participants actively initiate iterative reflection sessions or the application of insights and solutions to individuals and social entities not represented in a reflection session.

In a pull mechanism on the other hand, there are individuals or social entities who are interested in pulling together valuable observations and insights from others, and set up reflection sessions in which others act as reflection participants however, and others generate the outcomes. In such a mechanism, the driving force behind reflection is not the reflection participants, but actors outside the actual reflection process.

\section{Levels of Reflection}

It is clear, when analysing concrete observations or descriptions of reflection in practice, that there is such a thing as a "level" of reflection, in the sense of qualifying "how much" reflection occurs; how widereaching, how critically experiences are being reconsidered. There is a large body of work that characterizes reflection to consists of several phases and activities (Moon 1999; Fleck and Fitzpatrick 2010; Prilla et al. 2015). Existing models differ from each other in granularity and focus. For example, Moon (1999) and de Groot et al. (2013) focus on levels of reflection, van Woerkom and Croon (2008) emphasize criteria that help to identify reflection among people, and Fleck and Fitzpatrick (2010) describe a set of activities in reflection that can again be related to levels of reflection. In our work we aimed at describing levels and activities in reflection that help to identity whether and how reflection as described above is happening and where it needs to be support. As a result we created a three-step model of reflection activities (Prilla et al. 2015), which relates to the stages of "plan and do work" (level 1), "conduct reflection session" (level 2) and "apply outcomes" (level 3) of the CSRL model presented above (see Table 1).

\begin{tabular}{|l|l|}
\hline Level & Description \\
\hline $\mathbf{1}$ & $\begin{array}{l}\text { Describing experiences, emotions and rationales for action } \\
\text { (Boud 1985; Moon 1999; Tigelaar et al. 2008; Fleck and } \\
\text { Fitzpatrick 2010). }\end{array}$ \\
\hline $\mathbf{2 a}$ & $\begin{array}{l}\text { Referring to experiences by commenting and engaging in } \\
\text { reflection (Zhu 1996; Raelin 2002; Tigelaar et al. 2008; Fleck and } \\
\text { Fitzpatrick 2010; de Groot et al. 2013). }\end{array}$ \\
\hline $\mathbf{2 b}$ & $\begin{array}{l}\text { Referring to experiences and triggering interaction by asking for } \\
\text { information or feedback (Zhu 1996; van Woerkom and Croon }\end{array}$ \\
\hline
\end{tabular}




\begin{tabular}{|l|l|}
\hline $\mathbf{3}$ & 2008). \\
\hline $\begin{array}{l}\text { Creating results from reflection through drawing from } \\
\text { experiences and transforming insights into practice (Boud 1985; } \\
\text { Moon 1999; Fleck and Fitzpatrick 2010; de Groot et al. 2013). }\end{array}$ \\
\hline
\end{tabular}

Table 1. Three steps of reflection.

Each of the steps in this model has some substeps. For example, the step "referring to experiences" contains referring to experiences in different ways, including providing own experiences and challenging what has been said. Identifying these steps supports the analysis and design of reflection tools, as it allows for an understanding of what is happening in a tool and what needs to be supported to which extent (Prilla and Renner 2014; Fessl et al., 2015; Prilla et al. 2015).

\section{The Role of Articulation in the Reflection Process}

The concept of articulation as described by (Suchman 1996) plays a central role in reflection: Making the rationales behind experiences, perspectives and proposed solutions explicit supports the creation of insights both in individual and collaborative reflection. Activities such as (individual) writing what has happened in an experiences and how one perceived it triggers individual reflection processes (e.g., Scott 2010; Thorpe, 2004), and writing down ideas and perspectives on other experiences enables reflection participants to take the perspectives of others into account and arrive at a common solution (Boland and Tenkasi 1995; Prilla et al. 2012; Prilla et al. 2013b).

Regarding the CSRL model presented in this paper articulation plays a role as a trigger mechanism between stages (e.g. when experiences are documented and serve as data to reflect on) and as a medium for reflective thought and interaction in the "conduct reflection session" stage. As a consequence tool support needs to take articulation into account as a core concept to be supported, be it in terms of communication channels between people as needed in articulation among groups (Bannon and Schmidt 1992) or as personal notes for individual reflection.

The Role of Emotion in the Reflection Process

Emotion plays a dual role in the reflection process, one as part of the reflection objective (e.g. "emotion regulation"), and one as modulator of the reflection process itself. 


\section{Let's Talk about Reflection at Work}

Firstly, emotion impacts work performance by influencing e.g. creativity, memory, decision making and the repertoire of actions (e.g. biasing attention toward potential threats). This means that some emotions may be more desirable than others in the work situation. Appraisal of a situation and the labeling and articulation of the emotion experienced in the situation are important sources of information about an experience, in the situation or in retrospect. Awareness of one's own emotion might lead a person to want to change the emotion, especially to get out of a negative emotional state. As part of coping with work situations, people thus engage in emotion work, trying to either change the displayed feeling or to think differently about the situation in order to feel differently about it. Secondly, emotions are a resource for learning by directing attention to issues that need to be looked into. Furthermore, acknowledgement of emotions concerning an issue can help participants identify and express their views and concerns to colleagues, thus making the issue explicit and available for discussion and problem solving.

In (Krogstie \& Divitini, 2013), emotion has been linked in more detail to the CSRL model stages.

\section{Discussion \\ Combining individual/collaborative/organizational with reflection process/scope/learning}

Terminology as described above contains quite some complexity in those parts where we distinguish between individual and collaborative reflection processes, characterised essentially by who reflects, the scope of reflection, and the social entity who learns (individual, collaborative or organisational learning). This leads to several possible combinations of the terms "individual, collaborative, organisational" and "reflection process/scope/learning". Note that the only combination that we, after some discussion decided not to use, was "organisational reflection process"; as we see the process being defined by the reflection participants, who are either acting on their own (individual reflection process) or in a group (collaborative reflection process).

The following example illustrates the difference between who reflects, who should learn, and who learns: Assume that a team responsible for quality management reflects on existing rules for quality control and decides on some changes. Firstly, this is a collaborative reflection process. In addition, it is very likely that in parallel, individual reflection processes occur, as participants on their own, outside the collaborative reflection sessions, continue to reflect on issues under discussion. Results of the individual reflection processes may or may not be brought into the 
collaborative process again. Secondly, the scope of reflection was organizational in that ideally, when reflecting about quality control in an organization, the insights impact the organizational processes of quality control. Additionally it may well be that every member of the team learns for him- and herself (individual learning) or that the quality management team learns (collaborative learning, e.g., shared understanding within the team changes).

Establishing the distinction and cross-connections between who reflects (actors), who should learn (scope) and who learns/what is learned (outcome) is one of the key contributions of our work. At the same time it is one of the most interesting avenues for further research on computermediated reflective learning in social systems in our opinion.

What is specific about the workplace context?

In the simple cycle described within the CSRL model, reflective learning is related to working, planning work, or even simulating work. This is the concretisation of what is called "experience" in Boud et al.,'s (1985) model, or "concrete experience" in Kolb \& Fry (1979).

It is fair to ask, however, what about the terminology and model is specific to workplace settings?

The main answer is that we have developed the above terminology and model in parallel to empirical work, cooperative design work, and field trials which were all set in a workplace context. One can therefore quite safely assume the terminology and model to be relevant and expressive enough to talk about reflection in the workplace. This distinguishes the model from many other related works, and seemingly similar cyclic models for instance (see also the related work section below). Some elements of the model are very similarly found in literature on reflection in other domains, such as the stages of the model and might be more easily generalised again to considering other kinds of experiences than work experiences; other elements, like the information handed over, or most significantly the triggers are more unique to our theory and would hence require some more thought before generalisation.

We believe that it is mainly the social structures (division of labor, hierarchy) and the absence of pedagogical personnel as drivers of reflection that generate the specificities of the model for the workplace: All terminology that relates to reflection scope, the differentiation between individual, collaborative and organisational learning was developed exactly to take this into account. In addition, one can see that all triggers for new reflection cycles relate to involving other reflection participants; which may be more relevant in complex social structures. 
Designing socio-technical systems with the CSRL model as background The core theory (terminology and CSRL model) does not explicitly refer to technology. In this section, we discuss two relations between the CSRL model and technology.

Firstly, the stages in the CSRL model can be mapped to the potential roles of ICT in the stages. In previous work we have laid out, based on literature review and design-oriented methods (Krogstie et al., 2012b), the role of

ICT in relationship to CSRL model stages (Krogstie et al., 2012a; updated to take into account the matured CSRL model in Calori et al., 2014).

Summing up, we identified as the multiple roles of ICT in different stages of the CSRL model: to support the work processes; to collect data - either during working or during reflecting; to help analyse and make sense of data in order to reflect work processes as well as to preserve the rationale for outcomes from reflection; to trigger reflection sessions (e.g., by reminding to reflect); to coordinate reflection participants (e.g., support for scheduling, support for communication); to document the output generated by different stages of the CSRL model. Such a mapping is unique in literature; typically, specific technological functionalities are investigated with respect to their usefulness for reflection, such as automatic activity logging to support memory. Conversely, the above mapping aims to help both users and designers of technology to identify what functionalities are potentially helpful throughout connected working and reflection activities. Building up on the above conceptual work, we think that one interesting avenue for future research is to explore the function of technology in relationship to CSRL model stages empirically.

Secondly, the terminology and model can be used as useful language to talk about reflection in the process of designing new, or adapting and adopting existing technology for the purpose of reflective learning. Both terminology and model already form the basis of a significant body of literature that explores computer technology as support for reflective learning in the workplace (such as Balzert et al., 2012; Fessl et al., 2015; Mora et al., 2012; Müller et al., 2015; Pammer et al., 2015; Pitts et al., 2015; Prilla et al., 2015; Rivera-Pelayo et al., 2013; Sisarica et al., 2013). Furthermore, colleagues of us have created a toolbox that guides the design of technology for reflective learning; this toolbox was positively evaluated with four software development experts (Calori et al., 2014). One remaining and highly interesting issue for discussion is that learning, ultimately, needs to remain with the learner; otherwise, the object of discussion would not be computer-supported reflective learning by social entities, but machine learning with results being communicated to users. 
So far we have not considered systematically the line that fundamentally separates what activities and actions need to remain with the entity who shall learn (the single worker, the group, the organisation...), and what can be externalised to technology. This ultimate balance, that learning strongly requires activity on the user side in turn means that the design (adaptation, appropriation) of computing systems or single functionalities for reflective learning is at its core a socio-technical design task (as we have also argued in Prilla et al., 2013).

\section{The Role of Data and other Material in the Reflection Process}

Data and materials play a role in multiple stages in the CSRL model and have already appeared "on the sideline" in the above section on the role of ICT in the reflection process. In this section, we want to look more closely on data and material. By "data" we mean data that are automatically created by computing systems. By "material" we refer to physical or digital artefacts that are created by humans and that can be generated both during the plan and do work stage and during the conduct reflection stage. Data and materials originating from the plan and do work stage can be the basis for initiating a reflection cycle, and can additionally be used as reflection content in the reflection stage.

Data and materials, including annotations to existing data and materials, that originate from the reflection session and apply outcome step can be relevant for the actual integration of outcomes in the work activities by documenting the rationale of outcomes. This data and materials can also serve as input to subsequent reflection sessions.

Our deepest investigation of data has addressed data as reflection content: The quantified self and personal informatics research (see e.g., Choe et al., 2014; Li et al.,2010; Li et al., 2011) provides successful examples of how people generate data about their daily life, often in relationship to health or sustainable living, and use it as basis to reflect and change their behaviour for "the better" (healthier, more sustainable...). Manually or automatically created activity logs in this context serve the purpose to provide a data basis beyond memory for re-evaluating experiences. Colleagues have successfully used activity logging data about patient and carer interaction as basis for carers and care home facilities to monitor the quality of care (Müller et al., 2015). Usage was not long-term, however. In other cases, we have found it more difficult to replicate success. In Fessl et al. (2011) for instance, several barriers to the collection of biophysical data: wearing comfort, social acceptability of sensing, and direct relevance to work processes beyond personal interests. In Pammer \& Bratic (2013), we discuss the difficulty of deriving actionable knowledge from activity 
logging data in the case of time management even though users clearly understood activity logging data as well as their meaning for time management.

\section{Related Work: The CSRL model in the context of existing} theory

The CSRL model builds on a tradition of cyclic models of learning in which experience is considered in context of existing knowledge. As a result, new knowledge is produced and actions taken on the basis of this knowledge. , thus leading to new knowledge and new actions. The work of Dewey (1933) and that of Kolb and Fry (1975) form the basis of most more recent research: Dewey linked reflection and thinking and has a focus on the reflective attitude and skills of the learner and how a state of doubt, uncertainty and difficulty is the starting point for reflective thinking, as an element of experimental learning (Dewey, 1933). Dewey thus sees reflection as "Active, persistent and careful consideration of any belief or supposed form of knowledge in the light of the grounds that support it and further conclusions to which it leads..[].. it includes a conscious and voluntary effort to establish belief upon a firm basis of evidence and rationality". Kolb and Fry conceptualised experiential learning in the form of a cycle with four main steps: The learner has an experience, observes and reflects on the experience, forms abstract concepts and test them in new situations through active experimentation (Kolb, 1984; Kolb \& Fry, 1975). The re-evaluation of experience, including ideas, behaviour and feelings, and the creation of an outcome on basis of the re-evaluation, is cohesively addressed by Boud and colleagues (Boud et al. 1985) and has had a major influence on the development of the CSRL model. In particular, the consideration for affective elements is an important insight from Boud and colleagues.

Reflective learning in the workplace has seminally been explored by Argyris \& Schön (1996), whose main contribution to the discussion was the differentiation between reflection in-action and on-action. In the CSRL model, this is captured in the insight that a reflection session can be both brief/spontaneous/integral to work and more planned/structured/away from the immediate work setting.

The previously mentioned models focus on the individual learner; a second but largely disconnected scholarly discourse addresses reflection as a collaborative process, with key works being Cress \& Kimmerle (2008) as well as Stahl (2002). Cressey et al., (2006) discuss learning in organizations, considering productive reflection as the reflection being carried out in and on work as an element of this learning. Vince (2002) 
describe reflection in an organisation as an organizing process that questions assumptions, makes power relations visible, helps people manage anxieties and contributes to the democracy of the organization. Høyrup and Elkjær (2006) go into more detail on what characterises the individual, social relations and organizational perspectives on reflection. The CSRL model allows for the incorporation of a social and organizational perspective mainly by stressing transitions between cycles in the context of involving others in the organization for reflection and implementation of reflection outcomes.

In practice, reflective learning plays a major role in project management and quality assurance. In software engineering, project retrospectives are essentially reflection sessions. Research on project retrospectives typically emphasises specific techniques can be used to elicit and utilize reflection processes in teams (e.g. Dingsøyr 2005; Krogstie \& Divitini 2009). Professions characterized by a strong focus on human relations and people-directed activities such as mentoring, care, teaching have also developed insights and practices in the area of reflection. Teacher and nursing education have both contributed a substantial body of research on reflection related to work practice. An example of a practically oriented model of reflective learning is the What?-model of structured reflection proposed by Driscoll $(1994,2000)$, originating in research on professional development of nurses. The questions "What?", "So What" and "Now what" guide reflection on steps in the learning cycle.

\section{Conclusion}

In relation to the above discussed body of literature, the cycle model of reflective learning builds on stages that are easily related to other models. It adds an emphasis on information that needs to be handed over between stages and between reflection cycles, as well as on multiple possibilities to trigger reflection cycles that follow up on each other. From these core elements, our prior work spread out into multiple directions, all presented shortly in this paper, namely the question of who drives the reflection process (push vs pull), the roles of articulation and emotion in reflection. Additionally, we have discussed the subtleties of differentiating between reflection participants, reflection scope, and who actually learns; the specificity of our research for workplace learning, the relevance of these theoretical considerations for designing information and communication technology, and the role of data and materials in the reflection process. 


\section{Acknowledgements}

The authors wish to thank all collaborators in the MIRROR project, for a very fruitful and enjoyable four years. Most notably we would like to mention here, in alphabetical (second name) order: Roy Ackema, Michele Biole, Ulrike Cress, Krista de Leeuw, Martin Degeling, Hans Dirkzwager, Monica Divitini, Nils Faltin, Angela Fessl, Thomas Herrmann, Kristin Knipfer, Ellen Lenarts, Stefanie Lindstaedt, Neil Maiden, Simone Mora, Lars Müller, Lucia Pannese, Marco Parigi, Kristine Pitts, Kevin Pudney, Lisa Reinmann, Bettina Renner, Veronica Rivera-Pelayo, Malcolm Rose, Andreas Schmidt, Dominik Walter, Kos Zachos, Volker Ziegler. The project "MIRROR - Reflective learning at work" was funded under the FP7 of the European Commission (project number 257617). The KnowCenter is funded within the Austrian COMET Program -Competence Centers for Excellent Technologies - under the auspices of the Austrian Federal Ministry of Transport, Innovation and Technology, the Austrian Federal Ministry of Economy, Family and Youth and by the State of Styria. COMET is managed by the Austrian Research Promotion Agency FFG.

\section{References}

Argyris, Chris, and Donald Schön. Organizational Learning II. Theory, Method, and Practice. OD Series. Reading, MA, USA: Addison Wesley, 1996.

Balzert, Silke; Wessel, Daniel; Kleinert, Thomas; Knipfer, Kristin; and Fettke, Peter, "Towards an IT solution to support reflective learning at the workplace" (2012). ECIS 2012 Proceedings. Paper 70.

Bannon L, Schmidt K (1992) Taking CSCW Seriously: Supporting articulation work. Computer Supported Cooperative Work 1:7-40.

Boland RJ, Tenkasi RV (1995) Perspective making and perspective taking in communities of knowing. Organization science 6:350-372.

Boud, D., Garrick, J.: Understanding learning at work: Routledge (1999)

Boud, D., Keogh, R., Walker, D.: Promoting Reflection in Learning: a Model. In: Boud,D., Keogh,R., Walker, D. (eds): Reflection: Turning Experience into Learning. RoutledgeFalmer 1985.

Calori, Ilaria Canova; Divitini, Monica; Petersen, Sobah (Eds): Model of Computer Supported Reflective Learning - Version 2, D1.6 MIRROR.

Choe, E. K., Lee, N. B., Lee, B., Pratt, W. and Kientz, J. A. Understanding quantified-selfers' practices in collecting and exploring personal data. In Proc. SIGCHI'14, ACM, 1143-1152. 
Cress, Ulrike, and Joachim Kimmerle. "A Systemic and Cognitive View on Collaborative Knowledge Building in Wikis." Computer-Supported Collaborative Learning 3 (2008): 105-22.

Cressey, P.: Collective reflection and learning. In: Boud, D., Cressey, P. and Docherty, P.: Productive Reflection at Work. Routledge (2006)

Cressey, P., Boud, D. and Docherty, P.: The emergence of productive reflection. In: Productive Reflection at Work. Routledge 2006

Daudelin, M.W.: Learning from experience through reflection. Organizational Dynamics 24(3), 36\{48 (1996)

Dewey, John. How We Think. A Restatement of the Relation of Reflective Thinking to the Educative Process. (Revised edtn.). Boston: D. C. Heath, 1933.

Dingsøyr, Torgeir. "Postmortem Reviews: Purpose and Approaches in Software Engineering." Information and Software Technology 47 (2005): 293-303.

Driscoll, John. Practicing Clinical Supervision: A Reflective Approach. London: Bailliere Tindall (in association with the RCN), 2000.

Fessl, A.; Rivera-Pelayo, V.; Müller, L.; Pammer, V. \& Lindstaedt, S. Motivation and User Acceptance of Using Physiological Data to Support Individual Reflection 2nd International Workshop on Motivation and Affective Aspects in Technology Enhanced Learning (MATEL 2011), co-located with the Sixth European Conference on Technology Enhanced Learning (ECTEL 2011), 2011

Fessl, A.; Wesiak, G.; Rivera-Pelayo, V. \& Pammer, V. In-App Reflection Guidance for Workplace Learning Design for Teaching and Learning in a Networked World, Proceedings of the10th European Conference on Technology Enhanced Learning (ECTEL 2015), 2015, 85-99. DOI: 10.1007/978-3-319-24258-3 7

Fleck, R. \& Fitzpatrick, G. Supporting Collaborative Reflection with Passive Image Capture In Supplementary Proceedings of COOP'06, 2006, 41-48

Fleck R, Fitzpatrick G (2010) Reflecting on reflection: framing a design landscape. In: Proceedings of the 22nd Conference of the ComputerHuman Interaction Special Interest Group of Australia on ComputerHuman Interaction. ACM, Brisbane, Australia, pp 216-223

Høyrup, S. and Elkjær, B.: Reflection. Taking it beyond the individual. In: Boud, ., Cressey, P. and Docherty, P.: Productive Reflection at Work. Routledge 2006

Høyrup, S.: Employee-driven innovation and workplace learning: Basic concepts, approaches and themes. European Review of Labour and Research, 16(2) (2010) 
Kimmerle, J.; Cress, U. \& Held, C. The interplay between individual and collective knowledge: technologies for organisational learning and knowledge building Knowledge Management Research \&38; Practice, 2010, 8, 33-44

Knipfer, K., Kump, B., Wessel, D., Cress, U.: Reflection as catalyst for organisational learning. Studies in Continuing Education vol. 35: p. 19 (2012)

Kolb, D.A. Experiential Learning: Experience as a Source of Learning and Development. New Jersey: Prentice Hall, 1984.

Kolb, D.A., and R. Fry. "Towards an Applied Theory of Experiential Learning." In Theories of Group Processes, edited by C.L. Cooper, 3358. London: John Wiley, 1975.

Krogstie, Birgit R. "A Model of Retrospective Reflection in Project Based Learning Utilizing Historical Data in Collaborative Tools." Springer, 2009.

Krogstie, B.R., Divitini, M.: Supporting Reflection in Software Development with Everyday Working Tools. In Proceedings of COOP, France. Springer (2010)

Krogstie, B.R., Krogstie, J., Maiden, N., Lockerbie, J., Wessel, D., Knipfer, K. (2012a): Collaborative modelling of reflection to inform the development and evaluation of work-based learning technologies. IKNOW 2012:

Krogstie, B. R.; Prilla, M.; Wessel, D.; Knipfer, K. \& Pammer, V. (2012b) Computer Support for Reflective Learning in the Workplace: A Model 12th IEEE International Conference on Advanced Learning Technologies, ICALT 2012, Rome, Italy, July 4-6, 2012, 2012, 151153

Krogstie, Birgit, and Divitini, Monica. "Reflective Learning in the Workplace: The Role of Emotion." In Scaling up Learning for Sustained Impact. Proceedings of EC-TEL 2013, edited by HernandezLeo, Davinia, Ley, Tobias, Klamma, Ralf, and Harrer, Andreas, Vol. 8095. Lecture Notes in Computer Science. Springer, 2013.

Krogstie, B. R.; Prilla, M. \& Pammer, V. Understanding and Supporting Reflective Learning Processes in the Workplace: The CSRL Model Scaling up Learning for Sustained Impact - 8th European Conference, on Technology Enhanced Learning, EC-TEL 2013, Paphos, Cyprus, September 17-21, 2013, 2013, 151-164

Lin, X., Hmelo, C., Kinzer, C.K., Secules, T.J.: Designing Technology to Support Reflection. Educational Technology, Research and Development, 47(3), 1999 
Li, I., Dey, A. and Forlizzi, J. A stage-based model of personal informatics systems. In Proc. SIGCHI'10, ACM, 557-566.

Li, I.; Dey, A. K. \& Forlizzi, J. Understanding My Data, Myself: Supporting Self-reflection with Ubicomp Technologies Proceedings of the 13th International Conference on Ubiquitous Computing, ACM, 2011, 405-414

Mora, Simone; Boron, Alessandro; Divitini, Monica. (2012) CroMAR: Mobile augmented reality for supporting reflection on crowd management. International Journal of Mobile Human Computer Interaction. vol. 4 (2).

Müller, Lars; Divitini, Monica; Mora, Simone; Rivera-Pelayo, Verónica; Stork, Wilhelm. (2015) Context Becomes Content: Sensor Data for Computer-Supported Reflective Learning. IEEE Transactions on Learning Technologies. vol. 8 (1).

Pammer, V.; Knipfer, K.; Krogstie, B.; Wessel, D.; Prilla, M. \& Lindstaedt, S. Reflective Learning at Work - A Position and Discussion Paper Proceedings of the 1st European Workshop on Awareness and Reflection in Learning Networks (ARNETS'11, co-located with ECTEL'11), 2011, 790, 46-55

Pammer, V. \& Bratic, M. Surprise, surprise: activity log based time analytics for time management 2013 ACM SIGCHI Conference on Human Factors in Computing Systems, CHI '13, Paris, France, April 27 - May 2, 2013, Extended Abstracts, 2013, 211-216

Pammer, V.; Bratic, M.; Feyertag, S. \& Faltin, N. The Value of SelfTracking and the Added Value of Coaching in the Case of Improving Time Management Design for Teaching and Learning in a Networked World, Proceedings of the10th European Conference on Technology Enhanced Learning (ECTEL 2015), 2015, 467-472. DOI: 10.1007/9783-319-24258-3 41

Pitts, K., Pudney, K., Zachos, K., Maiden, N., Krogstie, B., Jones, S., Rose, M., Macmanus, J. and Turner, I. (01 Jan 2015). Using mobile devices and apps to support reflective learning about older people with dementia. Behaviour and Information Technology, 34(6), 613-631. DOI: 10.1080/0144929X.2015.1015165

Prilla, M.; Pammer, V. \& Balzert, S. The Push and Pull of Reflection in Workplace Learning: Designing to Support Transitions Between Individual, Collaborative and Organisational Learning 7th European Conference on Technology-Enhanced Learning (ECTEL 2012), 2012

Prilla M, Herrmann T, Degeling M (2013a) Collaborative Reflection for Learning at the Healthcare Workplace. CSCL@Work: Case Studies of Collaborative Learning at Work. 
Prilla, M.; Pammer, V. \& Krogstie, B. R (2013b). Fostering Collaborative Redesign of Work Practice: Challenges for Tools Supporting Reflection at Work ECSCW 2013: Proceedings of the 13th European Conference on Computer Supported Cooperative Work, 21-25 September 2013, Paphos, Cyprus, 2013, 249-268

Prilla M, Renner B (2014) Supporting Collaborative Reflection at Work: A Comparative Case Analysis. In: Proceedings of ACM Conference on Group Work (GROUP 2014). ACM.

Prilla M, Nolte A, Blunk O, et al (2015) Analyzing Collaborative Reflection Support: A Content Analysis Approach. In: Proceedings of the European Conference on Computer Supported Cooperative Work (ECSCW 2015).

Prilla, M. \& Wolf, C. Coflection - Combining Mutual Support and Facilitation in Technology Enhanced Learning. EC-TEL, Springer, 2015, 9307, 282-296

Raelin JA (2002) I don't have time to think!" versus the art of reflective practice. Reflections 4:66-79.

Rivera-Pelayo, V; Munk, J; Zacharias, V; and Braun, S. 2013. Live interest meter: learning from quantified feedback in mass lectures. In Proceedings of the Third International Conference on Learning Analytics and Knowledge (LAK '13), ACM, New York, NY, USA, 2327. DOI=http://dx.doi.org/10.1145/2460296.2460302

Rooksby, J; Rost, M; Morrison, A; and Chalmers, M. Personal Tracking As Lived Informatics. In Proc. of the 32nd Annual ACM Conference on Human Factors in Computing Systems (CHI`14), 2014. ACM, New York, NY, USA, 1163-1172.

Schön, D., The Reflective Practitioner, 1983: Basic Books, Inc.

Scott SG (2010) Enhancing Reflection Skills Through Learning Portfolios: An Empirical Test. Journal of Management Education 34:430-457.

Sisarica, A., Maiden, N., Morosini, D., Panesse, L., Pudney, K. and Rose, M. (2013). Creativity Support in a Serious Game for Dementia Care. 9th ACM Conference on Creativity \& Cognition, 17 Jun 2013, Sydney, Australia. DOI: 10.1145/2466627.2466668

Stahl, Gerry. "Building Collaborative Knowing." In What We Know About CSCL And Implementing It In Higher Education, edited by JanWillem Strijbos, Paul A. Kirschner, and Rob L. Martens, 53-85. Boston: Kluwer Academic Publishers, 2002.

Suchman, L. (1996). Supporting articulation work. Computerization and controversy: Value conflicts and social choices, 2, 407-423.

Thorpe, K. Reflective Learning Journals: from concept to practice. Reflective Practice, 2004, 5, 327-343 
Tigelaar D, Dolmans D, Meijer P, et al (2008) Teachers' Interactions and their Collaborative Reflection Processes during Peer Meetings. Advances in Health Sciences Education 13:289-308.

van Woerkom M, Croon M (2008) Operationalising critically reflective work behaviour. Personnel Review 37:317-331.

Vince, R. (2002): 'Organizing Reflection', Management Learning, 33,1: 63-78

White, B. Y.; Shimoda, T. A. \& Frederiksen, J. R. Enabling Students to Construct Theories of Collaborative Inquiry and Reflective Learning: Computer Support for Metacognitive Development International Journal of Artificial Intelligence in Education (IJAIED), 1999, 10, 151182

Xiao, L., Clark, S., Rosson, M.B., Carroll, J.M.: Promoting Reflective Thinking in Collaborative Learning Activities. ICALT 2008, Spain. IEEE (2008)

Zhu E (1996) Meaning Negotiation, Knowledge Construction, and Mentoring in a Distance Learning Course. In: Proceedings of Selected Research and Development Presentations at the 1996 National Coventions of the Association for Education Communications and Technology. 